\title{
Sexual attitudes and moral values: The importance of idealism and relativism
}

\author{
BETSY SINGH \\ Hampden-Sydney College, Hampden-Sydney, Virginia \\ and \\ DONELSON R. FORSYTH \\ Virginia Commonwealth University, Richmond, Virginia
}

\begin{abstract}
The present study tested a model of individual differences in moral thought, which assumes that attitudes concerning prescribed and proscribed social actions are part of an integrated conceptual system of personal ethics. When individuals who have varying personal moral philosophies were compared, those who emphasize the validity of fundamental moral principles (nonrelativists) expressed relatively negative attitudes about proscribed forms of sexual behavior, whereas relativists' reactions were more positive. The impact of relativism on attitudes, however, was tempered by idealism: when individuals endorsed highly idealistic ideologies, relativism was unrelated to attitudes. These findings suggest that variations in sexual attitudes are linked to in dividual differences in moral outlook.
\end{abstract}

Since the publication of Kinsey's research dealing with sexual behavior, many researchers have sought to uncover the reasons for widespread variations in sexual attitudes and behavior (Hendrick, Hendrick, Slapion-Foote, \& Foote, 1985; Kinsey, Pomeroy, \& Martin, 1948; Singh, 1980; Staples, 1978). The present study extended this research by presenting and testing a model of sexual attitudes based on personal moral philosophies. According to this model, attitudes concerning sexual practices are sustained by moral values that define a sense of right and wrong for the individual. Sexual attitudes are not isolated from other social attitudes, but instead are part of an integrated conceptual system of personal ethics. This integrated system, or personal moral philosophy, provides guidelines for moral judgments, solutions to ethical dilemmas, and prescriptions for actions in morally toned situations. Applied to variations in sexual attitudes, this model argues that individuals differ in their reactions to various types of sexual activities, such as premarital sex, extramarital sex, and sex between same-sexed individuals, because they endorse divergent personal moral philosophies.

Variations in personal moral philosophies can be conceptualized in a variety of ways (Gilligan, 1982; Haan, 1986; Hogan, 1973; Kohlberg, 1983; see Waterman, 1988 , for a review). Forsyth $(1980,1985)$, for example, offered a two-dimensional model based on relativism and idealism. Identified initially in an exploratory study of individual differences in judgments of psychological

The authors thank L. Diana, K. Singh, and J. S. Williams for their assistance with various aspects of this research. Reprint requests should be sent to Donelson R. Forsyth, Department of Psychology, Virginia Commonwealth University, Richmond, VA 23284-2018. research, these two dimensions parallel distinctions made by other theorists and researchers. In many cases, previous researchers have viewed these two aspects of morality as the endpoints of a single continuum, or as mutually exclusive categories. In contrast, Forsyth's twodimensional model of personal moral philosophies assumes that individuals range from high to low in their emphasis on principles and consequences. Thus, some personal moral codes emphasize the importance of universal ethical rules such as "Thou shalt not lie," whereas others maintain a posture of relativism that skeptically rejects universal principles. Second, a fundamental concern for the welfare of others lies at the heart of some individuals' moral codes, whereas others do not emphasize such humanitarian ideals; the former assume that we should avoid harming others, whereas the latter assume harm is sometimes necessary to produce good. Rather than classify individuals as either relativistic or idealistic, Forsyth assumed that these two dimensions interact to determine moral outlook.

To examine this interactional model, we assessed individual differences in personal moral philosophies, along with attitudes toward various sexual issues. Overall, we predicted that attitudes would be based more on relativism than on idealism: we expected individuals who endorse nonrelativistic moral philosophies to be more likely to express more conventional sexual attitudes. However, this overall impact of relativism should be tempered when idealism is high. Idealistic individuals generally base their judgments and actions on their relationships with, and responsibility to, other individuals. Thus, permissive sexual practices, such as extramarital and premarital sex, represent a strong violation of this ethic. Therefore, increases in idealism should be associated with decreases 
in permissiveness and mute the impact of relativism on attitudes.

\section{METHOD}

\section{Subjects}

The 182 female and 101 male participants were recruited from several sections of a college course dealing with human sexuality. Most (88.4\%) were between 17 and 24 years of age, were full-time students with no outside employment $(66.8 \%)$, and unmarried $(90.8 \%)$. The sample included 60 blacks, 209 whites, and 14 students from other racial groups.

\section{Procedure}

The subjects' ethical ideologies and attitudes toward extramarital sex, premarital sex, and homosexuality were assessed during the first week of the semester. Questionnaires were anonymous, and no incentives, such as extra credit, were offered to participants. Eleven of the individuals in the course declined to complete the forms.

Ethics Position Questionnaire. The subjects' ethical ideologies were assessed using the Ethics Position Questionnaire (EPQ). The EPQ consists of two 10-item scales that measure idealism and relativism (Forsyth, 1980). The idealism scale contains such items as "A person should make certain that their actions never intentionally harm another even to a small degree" and "If an action could harm an innocent other, then it should not be done." The relativism scale includes such items as "Different types of moralities cannot be compared as to "rightness", and "What is ethical varies from one situation to another." For all items, the subjects indicated degree of agreement or disagreement, using a 9point scale ranging from completely disagree to completely agree. Thus, scores on both scales can range from 10 to 90 (see Forsyth, Nye, \& Kelley, 1988, for more information).

Sexual attitudes. The subjects' attitudes toward extramarital sex, premarital sex, and homosexuality were assessed using items developed by the National Opinion Research Center. The item dealing with premarital sex asked, "If a man and woman have sex relations before marriage, do you think it is always wrong, almost always wrong, wrong only sometimes, or not wrong at all?" The extramarital sex item asked, "What is your opinion about a married person having sexual relations with someone other than the married partner?"' and used the response alternatives given above. The homosexuality item stated, "What about sexual relationships between two adults of the same sex-do you think it is:" and was followed by the same four alternatives.

\section{RESULTS}

The theory of personal moral philosophies on which the EPQ is based predicts that individuals' sexual attitudes are systematically related to their levels of idealism and relativism. To test this prediction, the subjects' sexual attitudes were examined through multiple regression. The three attitude measures served as the dependent variables, and gender, race (white vs. nonwhite), relativism, idealism, and the interactions of these variables served as the predictor variables.

\section{Multivariate Analysis}

The multivariate analysis revealed only two significant effects: a main effect of relativism and an interaction of relativism and idealism; the Pillai's trace approximations to the $F$ ratio $(d f=3,260)$ were 6.12 and 2.86 ( $p s<.001$ and .037), respectively. No other effects reached significance.

\section{Univariate Analyses}

All three attitude measures revealed similar trends, although these effects were strongest for attitudes toward extramarital sex and weakest for attitudes toward premarital sex. The relativism main effect was significant for attitudes toward extramarital and homosexual sex, and marginally significant for attitudes toward premarital sex $[F(1,262)=14.16,9.65$, and $3.24, p s<.001, .01$, and .08 , respectively]. Inspection of the beta weights and correlation coefficients indicates that increases in relativism were associated with increased acceptance of extramarital, homosexual, and premarital sex $(r s=.23, .34$, and .19 , respectively).

The relativism $\times$ idealism interaction was significant for attitudes toward extramarital sex, marginally significant for attitude toward homosexual sex, and nonsignificant for attitudes toward premarital sex $[F \mathrm{~s}(1,262)=$ $7.45,3.54$, and $1.07, p s<.01, .06$, and .31 , respectively]. Because the regression of idealism on sexual attitudes depends on the value of relativism (and vice versa), several conditional regression equations were calculated (see Cohen \& Cohen, 1983, pp. 320-325). Although the interaction of idealism and relativism produces a family of equations of regression lines with varying slopes and intercepts, by substituting certain values for relativism, we can identify several representative regression lines. Figures 1 and 2 present three such lines, one for a low relativism score (1 SD below the mean), one for an average relativism score (at the mean), and one for a high relativism score (1 $S D$ above the mean). Inspection of Figure 1 indicates that the strong relationship between relativism and attitude toward extramarital sex is apparent only at low levels of idealism: as relativists become more idealistic, they become increasingly negative toward extramarital sex. As a result, (1) high idealists, whether relativistic or nonrelativistic, adopted negative attitudes toward extramarital sex, and (2) high relativists who were not idealistic adopted the most positive attitudes. A similar effect held for attitudes toward homosexuality (see Figure 2), although in this case the overall impact of

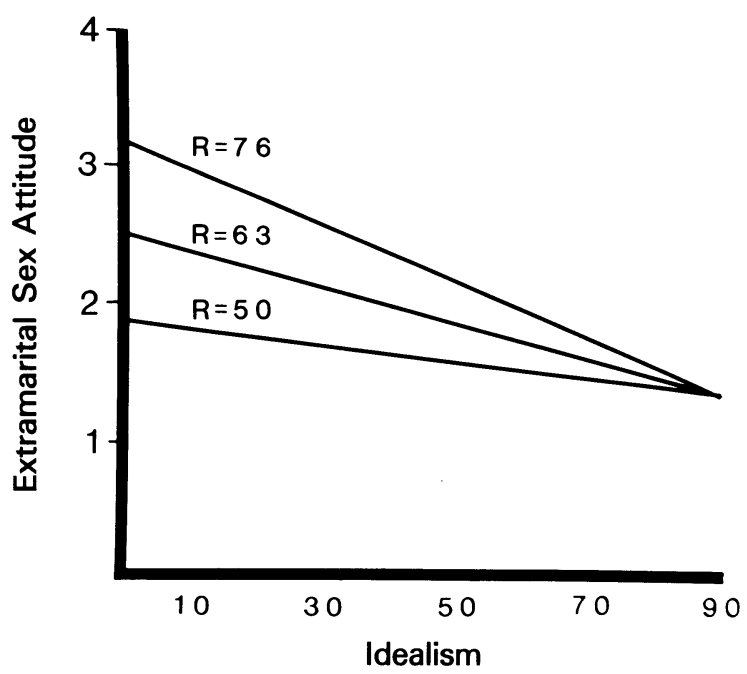

Figure 1. The conditional impact of idealism on attitudes toward extramarital sex at three levels of relativism (R): high (76), moderate (63), and low (50). 


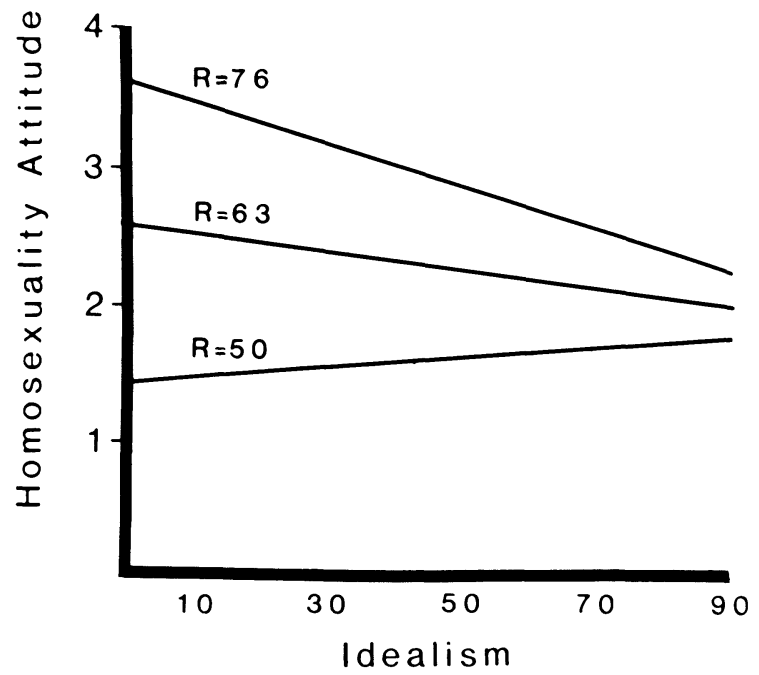

Figure 2. The conditional impact of idealism on attitudes toward homosexuality at three levels of relativism (R): high (76), moderate (63), and low (50).

relativism was somewhat greater. For extramarital sex, the regression lines eventually converge, whereas they do not for attitudes toward homosexuality.

\section{DISCUSSION}

In American society, some sexual practices (e.g., premarital sex) are proscribed by social norms, whereas others (e.g., marital sex) are prescribed and encouraged. Hence, it is not surprising that individuals who emphasize the validity of fundamental moral principles, norms, or laws (nonrelativists) have relatively negative attitudes about proscribed forms of sexual behavior. In contrast, individuals who challenge the value of universal moral norms endorse more permissive attitudes.

The impact of relativism on attitudes, however, was tempered by idealism. For two of the three sexual attitudes assessed, the link between relativism and attitude became progressively weaker as individuals endorsed increasingly idealistic moral philosophies. Particularly for attitudes toward extramarital sex, at extreme levels of idealism, the impact of relativism was negligible.

These findings suggest that variations in sexual attitudes are linked to individual differences in moral outlook. An individual who is faced with making a judgment about the "correctness" of a particular form of sexual interaction bases this judgment on his/her own individual system of ethics, and disagreements concerning sexuality must necessarily surface when personal moral philosophies are different. These results are also consistent with recent studies that focus more on the content of moral thought than on moral maturity. Gilligan (1982), for example, recently identified an "ethic of caring" that pervades moral processes. According to Gilligan, people vary in the extent to which they base their moral decisions on the principle that "inflicting hurt is ... selfish and immoral in its reflection of unconcern, while the expression of care is seen as the fulfillment of moral responsibility" (p. 73). Gilligan suggested that previous studies of moral thought have been so heavily influenced by Kohlberg's (1983) conception of social justice that the impact of an ethic of caring has been overlooked. Theoretically, Gilligan's ethic of caring appears to be conceptually similar to the idealism dimension.

\section{REFERENCES}

COHEN, J., \& COHEN, P. (1983). Applied multiple regression/correlation analysis for the behavioral sciences. Hillsdale, NJ: Erlbaum.

Forsyth, D. R. (1980). A taxonomy of ethical ideologies. Journal of Personality \& Social Psychology, 39, 175-184.

FORSYTH, D. R. (1985). Individual differences in information integration during moral judgment. Journal of Personality \& Social Psychology, 49, 264-272.

Forsyth, D. R., Nye, J. L., \& Kelley, K. (1988). Idealism, relativism, and the ethic of caring. Journal of Psychology, 122, 243-248.

Gilligan, C. (1982). In a different voice. Cambridge, MA: Harvard University Press.

HAAN, N. (1986). Systematic variability in the quality of moral action, as defined in two formulations. Journal of Personality \& Social Psychology, 50, 1271-1284.

Hendrick, S., Hendrick, C., Slapion-Foote, M. J., \& Foote, F. H. (1985). Gender differences in sexual attitudes. Journal of Personality \& Social Psychology, 48, 1630-1642.

HogAN, R. (1973). Moral conduct and moral character: A psychological perspective. Psychological Bulletin, 79, 217-232.

Kinsey, A. C., Pomeroy,W. B., \& Martin, C. E. (1948). Sexual behavior in the human male. Philadelphia: Saunders.

KoHLBERG, L. (1983). Essays in moral development (Vol. 2). New York: Harper \& Row.

SiNGH, B. K. (1980). Trends in attitudes toward premarital sexual relationships. Journal of Marriage \& the Family, 42, 387-393.

STAPLES, R. (1978). Race, liberalism-conservatism, and premarital sexual permissiveness: A biracial comparison. Journal of Marriage \& the Family, 40, 733-742.

Waterman, A. S. (1988). On the uses of psychological theory and research in the process of ethical inquiry. Psychological Bulletin, 107, 283-298.

(Manuscript received July 1, 1988.) 